University of Nebraska - Lincoln

DigitalCommons@University of Nebraska - Lincoln

Sociology Department, Faculty Publications

Sociology, Department of

2002

\title{
Familial and "On-the-Street" Risk Factors Associated with Alcohol Use among Homeless and Runaway Adolescents
}

\author{
Barbara J. McMorris \\ University of Washington, Seattle \\ Kimberly A. Tyler \\ University of Nebraska-Lincoln, kim@ktresearch.net \\ Les B. Whitbeck \\ University of Nebraska-Lincoln, Iwhitbeck2@unl.edu \\ Dan R. Hoyt \\ University of Nebraska-Lincoln, dhoyt2@unl.edu
}

Follow this and additional works at: https://digitalcommons.unl.edu/sociologyfacpub

Part of the Sociology Commons

McMorris, Barbara J.; Tyler, Kimberly A.; Whitbeck, Les B.; and Hoyt, Dan R., "Familial and "On-the-Street" Risk Factors Associated with Alcohol Use among Homeless and Runaway Adolescents" (2002). Sociology Department, Faculty Publications. 43.

https://digitalcommons.unl.edu/sociologyfacpub/43

This Article is brought to you for free and open access by the Sociology, Department of at DigitalCommons@University of Nebraska - Lincoln. It has been accepted for inclusion in Sociology Department, Faculty Publications by an authorized administrator of DigitalCommons@University of Nebraska - Lincoln. 


\title{
Familial and "On-the-Street" Risk Factors Associated with Alcohol Use among Homeless and Runaway Adolescents*
}

\author{
BARBARA J. McMORRIS, PH.D., ${ }^{\dagger}$ KIMBERLY A. TYLER, PH.D., ${ }^{\dagger}$ LES B. WHITBECK, PH.D., ${ }^{\dagger}$ AND DAN R. HOYT, PH.D. ${ }^{\dagger}$ \\ Social Development Research Group, University of Washington, 9725 Third Avenue NE, Suite 401, Seattle, Washington $98115-2024$
}

\begin{abstract}
Objective: This study investigated factors associated with alcohol use among homeless and runaway adolescents, using a riskamplification model. Method: Homeless and runaway adolescents $(N=$ $536,60 \%$ female) were recruited and interviewed by outreach workers directly on the streets, in shelters and in drop-in centers in four Midwestern states. The average age was 16 years; ages ranged from 12 to 22. Results: Parent alcohol problems were indirectly linked to adolescent drinking through familial abuse and its relationship to deviant peers, time on own and risky subsistence behaviors. Parent alcohol problems also predicted offspring alcohol use through parental rejection and its
\end{abstract}

association with deviant peers and with risky subsistence behaviors. The strongest direct effects on alcohol use were hanging out with antisocial friends and participating in deviant behaviors in order to survive on the street. Conclusions: This study sheds light on the nature of alcohol use in a high-risk population. Family background and "on-the-street" (time on own) factors must be taken into consideration when treating alcohol misuse in street youth. The alternative is a vicious cycle whereby homeless youth may become homeless adults. (J. Stud. Alcohol 63: 34-43, 2002)
A LCOHOL USE MAY SERVE a number of functions for members of a vulnerable population such as homeless and runaway adolescents. Victimization research posits that youth may turn to alcohol as a coping strategy to help deal with childhood trauma or as an escape mechanism from an abusive environment (Gomes-Schwartz et al., 1985; Harrison et al., 1997; Ireland and Widom, 1994; Lindberg and Distad, 1985). Drinking may diminish feelings of isolation or loneliness (Singer et al., 1989) or serve as self-medication to cope with negative life-events (Clark et al., 1997; Dembo et al., 2000; Hawke et al., 2000; Kilpatrick et al., 2000). Alcohol use may also represent another manifestation of antisocial behavior exhibited by youth who are participating in deviant behavior on the street, according to general deviance or problem behavior research (Gottfredson and Hirschi, 1990; Jessor and Jessor, 1977). Runaway and homeless adolescents clearly are a subgroup that faces a particularly high risk for engaging in a maladaptive, yet perhaps functional, behavior.

National surveys of alcohol use trends consistently find that adolescent alcohol drinking has declined since the $1980 \mathrm{~s}$ (Johnston et al., 2001). Despite this downward trend, alcohol use may be increasing among homeless and runaway

Received: May 11, 2001. Revision: October 4, 2001.

*This article is based on research supported by National Institute of Mental Health grant MH50140 to Les B. Whitbeck, principal investigator.

${ }^{\dagger}$ Correspondence should be directed to Barbara J. McMorris at the above address or via email at: mcmorris@u.washington.edu. Kimberly A. Tyler, Les B. Whitbeck and Dan R. Hoyt are with the Department of Sociology, University of Nebraska-Lincoln, Lincoln, NE. youth (Kipke et al., 1995a,b,c, 1997; Robertson, 1989; Windle, 1989), who are often not included in surveys. Rates of alcohol and drug use among street youth populations recently have been found to be substantially higher than those reported for the general adolescent population (Kipke et al., 1993; Smart and Adlaf, 1991; Yates et al., 1988). A recent purposive sample of homeless youth in 10 U.S. cities, for example, found alcohol prevalence rates ranging between 57\% (in shelter youth) and 81\% (in street youth) (Ringwalt et al., 1998).

This study investigates factors associated with alcohol use among homeless and runaway adolescents in the Midwest. Our primary goal is to examine the extent to which familial factors interact with the street environment to increase alcohol use in these youth. To accomplish this goal, we test a theoretical model that attempts to explain the interrelationships between these factors. The results may be helpful in providing information about the nature of alcohol use in a population of high-risk adolescents, in order to develop programs for prevention and early intervention.

\section{Theoretical model}

The current article proposes a risk amplification model, developed by Whitbeck and colleagues (1999), in which parent alcohol problems, physical and sexual abuse and/or parental rejection set in motion a negative chain of events. This leads to increased time spent on the street, affiliation with deviant friends and participation in survival strategies, resulting in the adverse developmental consequence of increased alcohol use for the adolescent (see Figure 1). We 
hypothesize a fully recursive model (i.e., all possible paths are hypothesized, with the exception of reciprocal paths) to investigate the cumulative effects of parental and time-onown risk factors on alcohol use. This model utilizes social interaction theory (Patterson, 1982) and life course developmental theory (Elder, 1998) to show how familial and time-on-own factors may result in alcohol misuse by homeless and runaway youth. We control for gender, age and race of the adolescents (paths not shown). Male adolescents tend to drink more frequently, in general, than female adolescents, and white adolescents tend to use alcohol more often than do blacks and Hispanics (Johnston et al., 2001); we expect these patterns to be similar in runaway and homeless youth. Age is also controlled because we expect older youth, having had more opportunity to spend time on the street, to report more frequent drinking than younger youth.

\section{Familial risk factors}

Research on the relation between family characteristics and adolescent substance use generally focuses on family alcohol and drug behavior, family bonding, parent-child in- teractions and family management techniques (Bahr et al., 1998; Baumrind, 1991; Chassin et al., 1996; Hawkins et al., 1992; Stice et al., 1993). Youth are more likely to use alcohol and other substances if family members are using (Ary et al., 1993; Brook and Brook, 1990; Kandel and Andrews, 1987; Sher et al., 1991). Children who have parents with alcohol problems are more likely to develop an alcohol or other drug use problem (Anderson and Harry, 1994; Brown et al., 1999; Cloninger et al., 1985; Russell et al., 1985); this finding was replicated in a sample of Hollywood homeless and runaway youth (Robertson et al., 1989).

A link also exists between parent alcohol problems and child abuse (Famularo et al., 1986). If parents with alcohol-related problems are more likely to abuse or neglect their children, multiple reasons exist for predicting that their offspring will be at increased risk for the development of alcohol problems (Widom et al., 1995). Many runaway and homeless adolescents come from abusive family backgrounds, and alcohol use is associated with a history of physical and sexual abuse among this population (Kipke et al., 1993; Rotheram-Borus et al., 1996). Estimates of physical or sexual abuse by parents or other family

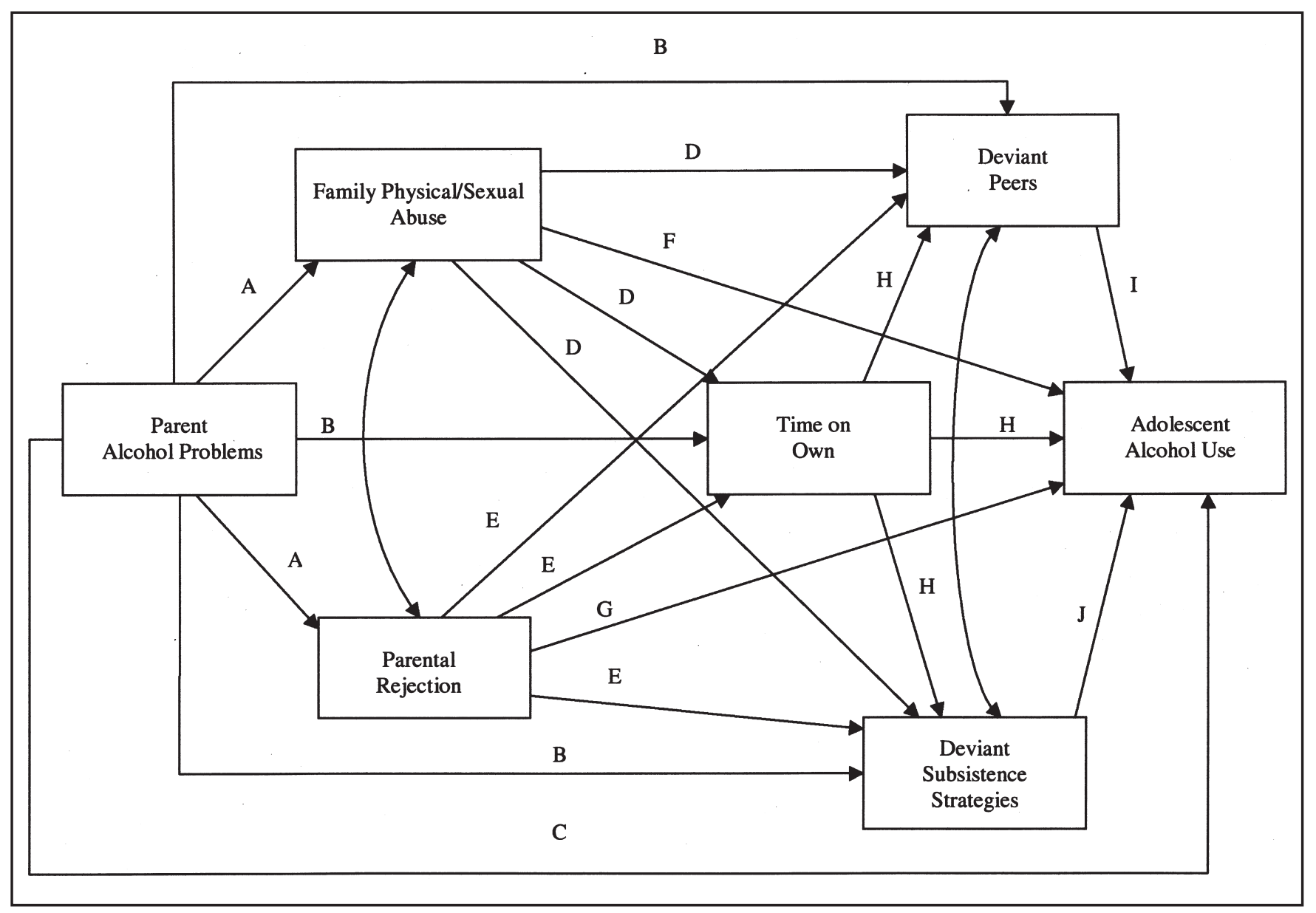

FiguRe 1. Hypothesized model 
members range from $25 \%$ to $75 \%$ (National Network of Runaway and Homeless Youths, 1991; Robertson, 1989; Smart and Ogburne, 1994; Welsh et al., 1995). This abuse is subsequently associated with the length of time the adolescent spends on the street after deciding to run away (Kufeldt and Nimmo, 1987; Whitbeck and Simons, 1990).

Although a history of family abuse is common, adolescents may leave their homes for related reasons. Some youth become homeless because they run away from home, whereas others experience rejection from their parents and are encouraged or forced to leave (Kipke et al., 1997). Also, evidence suggests that negative parenting styles in the forms of maternal rejection, parental conflict over child-rearing practices and inconsistent parenting (Brook et al., 1986; Vicary and Lerner, 1986) are positively related to adolescent alcohol use and other deviant behavior.

Coercive families, which may be characterized by alcohol problems, child abuse and negative parenting, provide "basic training" for antisocial behaviors, according to Patterson et al. (1984). Parents fail to utilize effective discipline strategies to deal with coercive exchanges between family members, and children learn to control through coercive techniques. These interaction styles are translated into other behavior contexts (e.g., peer relationships), in which coercive and abusive behaviors result in rejection by prosocial friends. As a result, youth may seek relationships with more marginalized peer groups (Dodge, 1983; Patterson, 1982). Persistent behavioral patterns are continually reinforced in interactions with others; this process is called "cumulative continuity" by Caspi et al. (1989). Adolescents who grow up in coercive families are likely to join social groups that display similar characteristics and engage in risky, deviant behaviors. Once on the street, these interaction styles are amplified and the risk for involvement in deviant behavior and alcohol use increases.

\section{Hypotheses related to familial risk factors}

As part of a coercive family framework, we predict parent alcohol problems to be positively associated with physical and sexual abuse and parental rejection (Figure 1, Arrows A). We hypothesize that parent alcohol problems will be positively related to street experiences through spending more time on the street (time on own), increased association with deviant peers and increased participation in deviant subsistence strategies (Arrows B). We also test for the direct effect of parent alcohol problems on subsequent adolescent alcohol use (Arrow C).

A history of family abuse is associated with running away numerous times, spending more time on the street (Janus et al., 1987; Whitbeck and Simons, 1990), associating with nonconventional peers (Silbert and Pines, 1981; Whitbeck and Simons, 1990; Whitbeck et al., 1997) and engaging in deviant subsistence strategies, including sur- vival sex (McCormack et al., 1986; Silbert and Pines, 1981; Whitbeck and Simons, 1993). Therefore, we hypothesize that family physical and sexual abuse will be positively related to antisocial friends, the amount of time youth spend on their own and engagement in deviant subsistent strategies (Arrows D). We also test for the direct effect of family abuse on adolescent alcohol use (Arrow F).

The quality of parenting is related to on-the-street experiences of runaway and homeless youth (Patterson, 1982; Whitbeck et al., 1997). We hypothesize that parental rejection will be positively related to the amount of time youth spend on the street, their deviant peer associations and their participation in deviant survival techniques (Arrows E) and also test for the direct effect of parental rejection on adolescent alcohol use (Arrow G).

\section{"Time on own" risk factors}

Although the risk for alcohol use may already be present among youth who run away from home or who are homeless, drinking may also occur as a response to situational factors associated with living on one's own. Kipke et al. (1993) found that length-of-time homeless was associated with alcohol use, in addition to involvement in survival sex or prostitution. This finding was echoed by Koopman et al. (1994), who showed that frequency of alcohol use was positively related to the number of sexual partners reported by runaways.

Hagan et al. (1997) demonstrated how life on the streets introduces adolescents to the need and opportunities for deviant behaviors (e.g., survival sex). Whitbeck and colleagues (Whitbeck and Hoyt, 1999; Whitbeck and Simons, 1993) expand on this relationship by stressing that few legitimate opportunities for supporting oneself occur on the street, which leads youth to rely instead upon deviant subsistence strategies, including stealing, selling sex and dealing drugs. Street youth also develop relationships and acceptance with similarly situated peers who are sources of support and information (Kipke et al., 1997), but who probably do not encourage prosocial behavior and are likely to be troubled themselves (Whitbeck and Hoyt, 1999). Research on peer influence more generally suggests that friends influence each other to engage in such problem behaviors as smoking, drinking and sex (Dinges and Oetting, 1993; Elliott et al., 1983; Ennett and Bauman, 1993).

Such behaviors as alcohol use, associating with deviant peers and engaging in deviant survival strategies are highly interrelated. The relationships between these three variables are congruent with problem behavior theory (Jessor and Jessor, 1977), which suggests that deviant behaviors are closely linked and tend to cluster together in individuals. MacLean et al. (1999) found that delinquency and aggression significantly predicted homeless adolescents' substance use. These relationships may also be indicative of "cumu- 
lative continuity" (Caspi and Bem, 1990): The pattern of life experiences and behaviors that led these adolescents to precocious independence also eliminated most legitimate means of support (Hagan et al., 1997; Whitbeck and Hoyt, 1999).

Life course theory (Elder, 1998) stresses that human development involves a dynamic process of personenvironment interactions that occur throughout the life course. People tend to select new environments that mimic old ones, and this selection process helps to reinforce and amplify existing behavioral dispositions (Caspi et al., 1989). This theory is applicable to the explanation of problems experienced by homeless and runaway youth: Many have abusive caretakers, and, once on their own, they tend to drift into situations that place them at risk for further abuse and victimization. Street culture promotes antisocial behavior, including association with deviant friends and deviant means of subsistence (e.g., prostitution, stealing and drug dealing). The cumulative impact of these factors places these youth at risk for alcohol misuse.

\section{Hypotheses related to time-on-own factors}

Spending more time on their own increases the opportunity for runaways to form ties to deviant peers and to engage in criminal street networks (Hagan et al., 1997; Whitbeck and Hoyt, 1999), as well as increases exposure and risk for alcohol use and abuse. We hypothesize that the amount of time on own will be positively associated with affiliations with deviant peers, deviant subsistence strategies and alcohol use (Arrows H). Problem behavior theory (Jessor and Jessor, 1977) suggests that deviant behaviors are part of underlying problem behavior syndrome and tend to cluster together in the same individual. To this end, we test for positive associations between deviant peers and alcohol use (Arrow I) and between deviant subsistence strategies and alcohol use (Arrow J).

\section{Method}

\section{Sample}

The total sample comprised 602 adolescents from the Midwest Homeless and Runaway Adolescent Project (MHRAP), a four-state study of runaway adolescents from Missouri, Iowa, Nebraska and Kansas. Young people were interviewed by trained outreach youth-workers with considerable experience interviewing and interacting with this population; interviews took place directly on the streets, in shelters and in drop-in centers. Recruitment of participants occurred as part of the participating agencies' regular intake and outreach programs. Agencies were selected for participation in the study, in fact, based on their having an existing street outreach program in addition to shelter and/ or transitional living facilities. A total of six agencies participated in recruitment efforts: two in St. Louis (Missouri) and one each in Kansas City (Missouri), Wichita (Kansas), Lincoln (Nebraska), and Des Moines (Iowa).

Adolescents signed a consent form prior to starting the interview and, because they were not living under parental supervision at the time of the interview, they were treated as emancipated. Referral and support services were offered to youth on the street and provided to youth in shelters by the agencies as part of their outreach programs. Agreeing to be interviewed was not a precondition for any of the services the agencies provided. Interviews were structured and typically lasted about 90 minutes. Respondents received a snack during a break in the interview process and $\$ 15$ for their participation.

\section{Participants}

Response rates ranged from $71 \%$ to $100 \%$ by agency. The average response rate across all agencies was $93 \%$. Of the total 602 adolescents interviewed, $361(60 \%)$ were female and $241(40 \%)$ were male. The majority of adolescents were either white $(61 \%)$ or black $(24 \%)$. The youth ranged in age from 12 to 22 years, with a mean of 16 years. The total amount of time away from home (time on the street, time in shelters and other institutions, time with friends and relatives) ranged from 1 day to over 7.5 years, with a median of 61 days. Prior to running away for the first time, $55 \%$ of adolescents were from a metropolitan area or suburb of a metropolitan area of 100,000 people or more. Another $20 \%$ said they had lived in cities with populations from 50,000 to 100,000 ; the remaining $25 \%$ were from towns of 50,000 or less.

\section{Measures}

Dependent variable. Adolescent alcohol use was measured using two items in which respondents were asked about frequency of use of beer and distilled spirits during the past 12 months. The response categories ranged from 0 (never) to 6 (daily). The two items were summed so that the higher the score, the more frequent the use of alcohol. The correlation between these two items was 0.73 . Three quarters of our sample reported they had used beer and almost two thirds $(66 \%)$ had used distilled spirits at least once in the last year. Over one fifth of adolescents used beer $(25 \%)$ or distilled spirits $(18 \%)$ weekly or more often. These rates are similar to levels of alcohol use $(72 \%$ in the past 3 months) reported by MacLean et al. (1999) in their study of runaways in Seattle.

Control variables. Gender, race and a continuous measure of age were controlled for in the model. Gender was coded 0 for males and 1 for females, and race was coded 0 for nonwhites and 1 for whites. 
Familial factors. Parent alcohol problems were measured by asking adolescents, "As far as you know, has your biological mother and/or father ever had an alcohol problem?" The response categories were 0 (neither parent had a problem with alcohol), 1 (at least one parent had an alcohol problem) and 2 (both parents had alcohol problems).

The family abuse measure was an 11-item scale that asked adolescents how often a parent or adult caretaker who was supposed to be taking care of them ever threw something at them in anger, pushed them, slapped them, hit them with an object, beat them up with their fists, threatened or assaulted them with a weapon and/or sexually abused them. The responses on individual items ranged from 0 (never) to 3 (many times). Because an unequal number of physical abuse versus sexual abuse items were asked, items were weighted to give equal importance to both sexual and physical abuse indicators in the summed scale. Due to a skewed distribution, we used the natural logarithm of the summed scale in the following analysis. Scale scores were coded such that the higher the score, the higher the abuse. Cronbach's alpha for family abuse was 0.83 in this sample (physical abuse items adapted from Straus and Gelles, 1990; sexual abuse items adapted from Whitbeck and Simons, 1990).

Elliott's parental rejection scale (Brennen, 1974) measured the quality of the parent-child relationship. The fiveitem scale assessed the perceived amount of care and trust the parent had for the adolescent and the extent to which the parent blames the adolescent. Response categories ranged from 1 (strongly agree) to 5 (strongly disagree). Certain items were reverse-coded such that the higher the scale score, the higher the rejection. Cronbach's alpha was 0.79 .

Time-on-own factors. Time on own was the total amount of time the respondent had been on the street or in unsupervised living arrangements (e.g., staying with friends) since first running away from home. Because of the skewed nature of reports, we computed the time-on-own measure as the logarithm of the total number of days of unsupervised living arrangements.

Deviant peers was measured using 13 items asking whether any of the respondents' close friends had ever sold drugs, used drugs, broke in and took things from a house or store, sold sexual favors or threatened and/or assaulted someone with a weapon $(0=$ no; $1=$ yes) (adapted from Whitbeck and Simons, 1990). The items were weighted to give equal weight to sexual and nonsexual deviance. Cronbach's alpha for this measure was 0.89 .

Deviant subsistence strategies consisted of 15 dichotomous items that focused on different tactics that adolescents may have used since being on the street, in order to survive (adapted from Whitbeck and Simons, 1990; Cronbach's alpha $=0.81$ ). Respondents were asked, for example, to indicate whether they had conned someone, robbed someone, sold sex and/or panhandled. Items were weighted to give equal weight to sexual and nonsexual items, and the natural logarithm of this variable was computed because of its skewed distribution.

\section{Results}

Descriptive statistics and Pearson correlation coefficients for the measures used in the present analysis are presented in Table 1. After listwise deletion of missing cases, the present analyses comprised 536 young people. At the bivariate level, parent alcohol use was significantly associated with family abuse $(r=0.21, p<.01)$, parental rejection $(r=0.15, p<.01)$, deviant peers $(r=0.13, p<.01)$ and adolescent alcohol use $(r=0.12, p<.01)$. Adolescent use of alcohol was also significantly related to parental rejection $(r=0.13, p<.01)$ and the number of days youth spent on their own $(r=0.19, p<.01)$. Alcohol use, predictably, was strongly associated with deviant peers $(r=0.42, p<$ $.01)$ and deviant subsistence strategies $(r=0.43, p<.01)$.

TABLE 1. Correlation matrix for adolescent alcohol use

\begin{tabular}{|c|c|c|c|c|c|c|c|c|c|c|}
\hline & 1 & 2 & 3 & 4 & 5 & 6 & 7 & 8 & 9 & 10 \\
\hline 1. Gender $(1=$ female $)$ & - & & & & & & & & & \\
\hline 2. Age & $-0.13^{\dagger}$ & - & & & & & & & & \\
\hline 3. Race $(1=$ white $)$ & $0.10^{*}$ & 0.00 & - & & & & & & & \\
\hline 4. Parent alcohol prob. & 0.08 & 0.02 & $0.14^{\dagger}$ & - & & & & & & \\
\hline 5. Family abuse & $0.21^{\dagger}$ & $0.15^{\dagger}$ & $0.09 *$ & $0.21^{\dagger}$ & - & & & & & \\
\hline 6. Parental rejection & $0.14^{\dagger}$ & 0.05 & $0.11^{\dagger}$ & $0.15^{\dagger}$ & $0.31^{\dagger}$ & - & & & & \\
\hline 7. Time on own & $-0.10^{*}$ & $0.37^{\dagger}$ & -0.01 & 0.05 & $0.17^{\dagger}$ & 0.08 & - & & & \\
\hline 8. Deviant peers & -0.01 & $0.21^{\dagger}$ & 0.05 & $0.13^{\dagger}$ & $0.30^{\dagger}$ & $0.18^{\dagger}$ & $0.22^{\dagger}$ & - & & \\
\hline 9. Deviant subst. strategies & $-0.28^{\dagger}$ & $0.10^{*}$ & -0.01 & 0.06 & $0.10^{*}$ & $0.12^{\dagger}$ & $0.12^{\dagger}$ & $0.46^{\dagger}$ & - & \\
\hline 10. Adolescent alcohol use & $-0.13^{\dagger}$ & $0.15^{\dagger}$ & $0.09 *$ & $0.12^{\dagger}$ & 0.07 & $0.13^{\dagger}$ & $0.19^{\dagger}$ & $0.42^{\dagger}$ & $0.43^{\dagger}$ & - \\
\hline Mean & 0.60 & 16.23 & 0.61 & 0.77 & 0.46 & 14.06 & 4.06 & 0.45 & 0.11 & 3.97 \\
\hline (SD) & $(0.49)$ & $(1.88)$ & $(0.49)$ & $(0.75)$ & $(0.33)$ & $(4.46)$ & $(1.78)$ & $(0.27)$ & $(0.14)$ & $(3.10)$ \\
\hline Range & $0-1$ & $12-22$ & $0-1$ & $0-2$ & $0-1.34$ & $5-25$ & $0-7.92$ & $0-1$ & $0-0.64$ & $0-12$ \\
\hline
\end{tabular}

Note: $N=536 .{ }^{*} p<.05 ;{ }^{\dagger} p<.01$. 
Figure 2 shows the results of the path analysis (only significant paths shown). The standardized path coefficients, $\beta$, represent the effect of a given predictor variable on the dependent variable after accounting for the remaining relationships in the model. Because some of the variables were dichotomous, this model was estimated using the maximum likelihood procedure in LISREL 8 (Jöreskog and Sörbom, 1993).

This multivariate model revealed that parent alcohol problems were positively linked to both early family abuse $(\beta=$ $0.17, p<.01)$ and parental rejection $(\beta=0.11, p<.01)$, indicating that adolescents with alcoholism-prone parents experience higher rates of abuse and rejection. Adolescents reporting high levels of parental rejection were more likely to hang out with antisocial friends $(\beta=0.09, p<.05)$ and to engage in deviant behavior in order to survive on the streets $(\beta=0.13, p<.01)$ than runaway youth not rejected by their parents. Young people who experienced higher rates of family abuse were also more likely to connect with deviant peers $(\beta=0.23, p<.01)$, engage in deviant subsistence strategies $(\beta=0.16, p<.01)$ and spend more time on their own $(\beta=0.14, p<.01)$ than those who reported lower levels of family abuse. The greater the length of time on their own, the greater the likelihood of adolescents hanging out with antisocial friends $(\beta=0.12, p<.01)$ and using alcohol $(\beta=0.09, p<.05)$. As predicted, associating with deviant friends and engaging in antisocial behaviors on the street were both strongly related to adolescent alcohol use $(\beta=0.28, p<.01 ; \beta=0.27, p<.01$, respectively).

The decomposition of the effects of independent variables on the dependent variables (Jöreskog and Sörbom, 1993) in Table 2 suggests several themes. First, the effects of parent alcohol problems, family abuse and parental rejection on adolescent alcohol use were indirect through the other components in the model, as well as similar in magnitude. In particular, the zero-order correlation of parent alcohol problems with offspring drinking was entirely mediated by the effects of intervening variables. Second, the effects of time spent on the street (time on own) on drinking were fairly divided between a direct and an indirect effect. Time spent on the street directly and indirectly impacts alcohol use through deviant friends but not through deviant survival behaviors, as expected. Third, the strongest direct paths to alcohol use in this model occur for the more proximal deviant behaviors engaged in on the street:

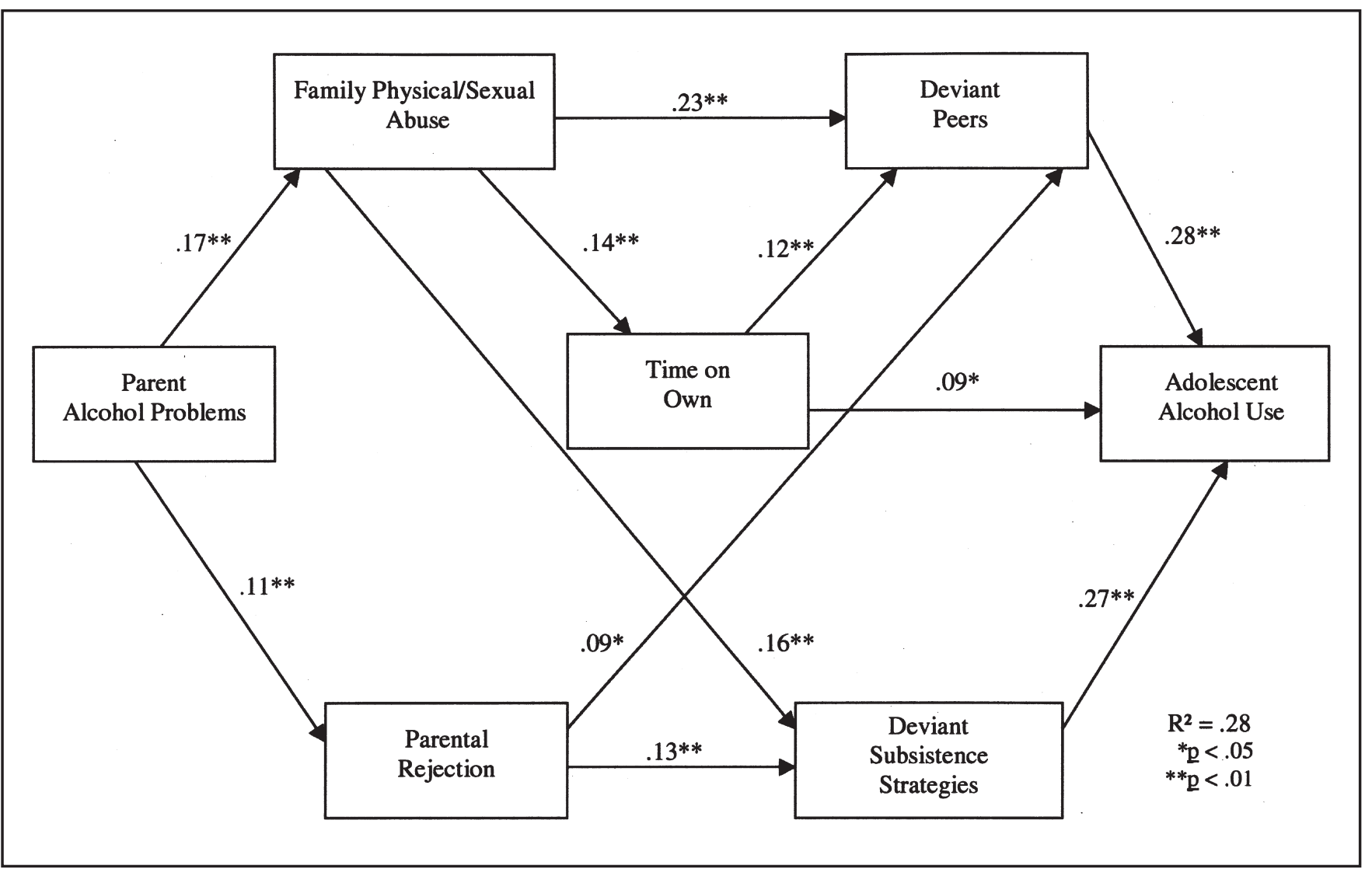

FiguRE 2. Path model for adolescent alcohol use (only significant paths shown) 


\begin{tabular}{|c|c|c|c|c|c|c|}
\hline & $\begin{array}{l}\text { Early family } \\
\text { abuse }\end{array}$ & $\begin{array}{l}\text { Parental } \\
\text { rejection }\end{array}$ & $\begin{array}{c}\text { Time on } \\
\text { own }\end{array}$ & $\begin{array}{c}\text { Deviant } \\
\text { peers }\end{array}$ & $\begin{array}{c}\text { Deviant subsist. } \\
\text { strat. }\end{array}$ & $\begin{array}{l}\text { Adolescent } \\
\text { alcohol use }\end{array}$ \\
\hline \multicolumn{7}{|l|}{ Gender } \\
\hline Direct & $.27^{\dagger}$ & $.16^{\dagger}$ & $-.12^{\dagger}$ & -.06 & $-.42^{\dagger}$ & -.05 \\
\hline Indirect & .00 & .00 & $.04^{\dagger}$ & $.07^{\dagger}$ & $.06^{\dagger}$ & $-.11^{\dagger}$ \\
\hline Total & $.27^{\dagger}$ & $.16^{\dagger}$ & -.07 & .01 & $-.36^{\dagger}$ & $-.17^{\dagger}$ \\
\hline \multicolumn{7}{|l|}{ Age } \\
\hline Direct & $.19^{\dagger}$ & .07 & $.32^{\dagger}$ & $.12^{\dagger}$ & -.02 & .03 \\
\hline Indirect & .00 & .00 & $.03^{\dagger}$ & $.09^{\dagger}$ & $.05^{\dagger}$ & $.09^{\dagger}$ \\
\hline Total & $.19^{\dagger}$ & .07 & $.35^{\dagger}$ & $.21^{\dagger}$ & .03 & $.12^{\dagger}$ \\
\hline \multicolumn{7}{|l|}{ Race } \\
\hline Direct & .04 & $.10 *$ & -.02 & .03 & .01 & $.09 *$ \\
\hline Indirect & .00 & .00 & .01 & .02 & .02 & .02 \\
\hline Total & .04 & $.10^{*}$ & -.02 & .05 & .03 & $.11^{\dagger}$ \\
\hline \multicolumn{7}{|c|}{$\begin{array}{l}\text { Parental alcohol } \\
\text { problems }\end{array}$} \\
\hline Direct & $.17^{\dagger}$ & $.11^{\dagger}$ & .02 & .06 & .05 & .06 \\
\hline Indirect & .00 & .00 & $.03^{\dagger}$ & $.06^{\dagger}$ & $.04^{\dagger}$ & $.05^{*}$ \\
\hline Total & $.17^{\dagger}$ & $.11^{\dagger}$ & .05 & $.11^{\dagger}$ & $.09 *$ & $.11^{\dagger}$ \\
\hline \multicolumn{7}{|c|}{ Early family abuse } \\
\hline Direct & & & $.14^{\dagger}$ & $.23^{\dagger}$ & $.16^{\dagger}$ & -.08 \\
\hline Indirect & & & .00 & $.02 *$ & .01 & $.12^{\dagger}$ \\
\hline Total & & & $.14^{\dagger}$ & $.25^{\dagger}$ & $.17^{\dagger}$ & .04 \\
\hline \multicolumn{7}{|c|}{ Parental rejection } \\
\hline Direct & & & .04 & $.09 *$ & $.13^{\dagger}$ & .05 \\
\hline Indirect & & & .00 & .00 & .00 & $.06^{\dagger}$ \\
\hline Total & & & .04 & $.10^{*}$ & $.13^{\dagger}$ & $.12^{\dagger}$ \\
\hline \multicolumn{7}{|l|}{ Time on own } \\
\hline Direct & & & & $.12^{\dagger}$ & .04 & $.09 *$ \\
\hline Indirect & & & & .00 & .00 & $.04 *$ \\
\hline Total & & & & $.12^{\dagger}$ & .04 & $.13^{\dagger}$ \\
\hline \multicolumn{7}{|c|}{ Deviant peers } \\
\hline Direct & & & & & & $.28^{\dagger}$ \\
\hline Indirect & & & & & & .00 \\
\hline Total & & & & & & $.28^{\dagger}$ \\
\hline \multicolumn{7}{|c|}{$\begin{array}{l}\text { Deviant subsistence } \\
\text { strategies }\end{array}$} \\
\hline Direct & & & & & & $.27^{\dagger}$ \\
\hline Indirect & & & & & & .00 \\
\hline Total & & & & & & $.27^{\dagger}$ \\
\hline
\end{tabular}

Note: $N=536 .{ }^{*} p<.05 ;{ }^{\dagger} p<.01$.

Associating with antisocial friends and engaging in survival behavior both yielded the largest path coefficients.

\section{Discussion}

The current study sheds light on the nature of alcohol use in a high-risk population. Parent alcohol problems, rejection, and sexual and physical abuse characterize the backgrounds of runaway and homeless youth and propel them out on their own, where they are faced with the pressures of surviving on the street or in shelters. Our analysis indicates that parent alcohol problems indirectly affect adolescent alcohol use through abusive and rejecting care-taking behavior, both of which increase the likelihood of spending time on the street, associating with deviant friends and engaging in deviant survival techniques. Although we do not have measures of drinking motives, we speculate that for many youth, alcohol use serves as a coping mechanism for the dysfunctional families that they have left, as well as a mechanism for dealing with the harsh reality of life on the street.

The present findings provide support for a risk amplification approach to explaining alcohol use among runaway and homeless adolescents. An already negative developmental trajectory, established by a maladaptive family background including parental alcohol use, abuse and rejection, is accentuated by what adolescents experience on the street. These results echo Caspi and Bem's (1990) notion of "cumulative continuity," as well as Patterson's (1982) social interaction theory. Street experiences help to exacerbate and habitualize negative or coercive interaction styles that result in antisocial behavior, including alcohol use.

We temper our findings with a consideration of limitations. First, our sample of runaway and homeless youth is not a probability sample. It is difficult to determine how representative the sample is of this high-risk population. 
The data were collected at multiple sites in four states, however, which adds to their credibility and generalizability. Second, our measures were created using adolescents' selfreported data on their own and their parents' behavior, and may be somewhat biased. Common method variance problems may result, although we do have some evidence of concurrence between parent/caretaker reports and adolescent reports of abuse in prior work (Whitbeck et al., 1997). Third, our analysis is based on cross-sectional data that do not lend themselves to causal arguments, although they are good for generating hypotheses. Thus, it is difficult to unravel temporal relationships among family environment, street environment and alcohol use. Decomposition of effects suggests that intervening effects of street experiences on the relationship between family factors and adolescent alcohol use are significant. Longitudinal data would be necessary to establish these causal relations, however. Fourth, our lack of a standardized interview with proven reliability and validity is a limitation: We lack measures of DSM-IV criteria for disorders in adolescents and their parents that may be helpful in untangling underlying temperament factors from contextual effects. Last, our measure of adolescent alcohol use asks about drinking in the past year, whereas the median length of time spent on the street is 61 days. This raises the issue that a substantial amount of drinking behavior may have occurred before the adolescent was on the street.

Despite these limitations, our findings provide important information about the nature of alcohol use among street youth. Homelessness obviously disrupts healthy adolescent development (Farrow et al., 1992), and homeless youth misusing alcohol and other drugs and left untreated may get caught in a vicious circle and go on to become chemically dependent and chronically homeless adults. In addition, the use of alcohol and other drugs is likely to put homeless youth at an increased risk for a wide range of physical and mental health problems and involvement in criminal activities. Alcohol misuse may also destabilize the lives of homeless youth, making it difficult for them to be reunited with families or to make the transition off the street and into more stable living situations (Kipke et al., 1993).

Alcohol and other drug problem assessment, referral and treatment should be integrated into outreach and shelter settings. According to Smart and Ogborne (1994), treatment episodes for youth with both alcohol-use problems and street-youth characteristics tend to be brief and to terminate prematurely. This suggests the need for more experimentation in the delivery of youth services (e.g., planned brief interventions, use of outreach workers to maintain contact with youth and the establishment of long-term supportive residences). In line with our finding of a strong relationship between deviant peers and drinking, Koopman et al. (1994) suggest that treatment should also include the development of coping skills, to resist the intense social pressure youth are likely to encounter to use alcohol and other drugs on the streets. Our depiction of family characteristics of homeless and runaway youth indicates that, if adolescents are to return home, they and their families will need intensive counseling on a wide range of issues, including parental rejection, anger management and abuse issues, as well as drug treatment services (Ringwalt et al., 1998).

\section{References}

Anderson, A.R. And Henry, C.S. Family system characteristics and parental behaviors as predictors of adolescent substance use. Adolescence 29: 405-420, 1994.

Ary, D.V., Tildesley, E., Hops, H. And Andrews, J.A. The influence of parent, sibling, and peer modeling and attitudes on adolescent use of alcohol. Int. J. Addict. 28: 853-880, 1993.

Bahr, S.J., Maughan, S.L., Marcos, A.C. and Li, B. Family, religiosity, and the risk of adolescent drug use. J. Marr. Fam. 60: 979-992, 1998.

BAUMRIND, D. The influence of parenting style on adolescent competence and substance use. J. Early Adolesc. 11: 56-95, 1991.

Brennon, T. Evaluation and Validation Regarding the National Strategy for Youth Development, Boulder, CO: Behavioral Research Evaluation Program, University of Colorado, 1974.

Brook, D.W. And Brook, J.S. The etiology and consequences of adolescent drug use. In: Watson, R.R. (Ed.) Drug and Alcohol Abuse Prevention, Totowa, NJ: Humana Press, 1990, pp. 339-362.

Brook, J.S., Whiteman, M., Gordon, A.S., Nomura, C. and Brook, D.W. Onset of adolescent drinking: A longitudinal study of intrapersonal and interpersonal antecedents. Adv. Alcohol Subst. Abuse 5: 91-110, 1986.

Brown, S.A., Tate, S.R., Vik, P.W., Haas, A.L. and Aarons, G.A. Modeling of alcohol use mediates the effect of family history of alcoholism on adolescent alcohol expectancies. Exp. Clin. Psychopharmacol. 7: 20-27, 1999.

Caspi, A. And Bem, D.J. Personality continuity and change across the life course. In: Pervin, L.A. (Ed.) Handbook of Personality: Theory and Research, New York: Guilford Press, 1990, pp. 549-575.

Caspi, A., Bem, D.J. and Elder, G.H. Continuities and consequences of interactional styles across the life course. J. Pers. 57: 375-406, 1989.

Chassin, L., Curran, P.J., Hussong, A.M. and Colder, C.R. The relation of parent alcoholism to adolescent substance use: A longitudinal follow-up study. J. Abnorm. Psychol. 105: 70-80, 1996.

Clark, D.B., Lesnick, L. And Hegedus, A.M. Traumas and other adverse life events in adolescents with alcohol abuse and dependence. J. Amer. Acad. Child Adolesc. Psychiat. 36: 1744-1751, 1997.

Cloninger, C.R., Bohman, M., Sigvardsson, S. and von Knorring, A.-L. Psychopathology in adopted-out children of alcoholics: The Stockholm Adoption Study. In: Galanter, M. (Ed.) Recent Developments in Alcoholism, Vol. 3, New York: Plenum Press, 1985, pp. 37-51.

Dembo, R., Wothke, W., Shemwell, M., Pacheco, K., Seeberger, W., Rollie, M., Schmeidler, J. And Livingston, S.J. A structural model of the influence of family problems and child abuse factors on serious delinquency among youths processed at a juvenile assessment center. J. Child. Adolesc. Subst. Abuse 10 (1): 17-31, 2000.

Dinges, M.M. And Oetting, E.R. Similarity in drug use patterns between adolescents and their friends. Adolescence 28: 253-266, 1993.

Dodge, K.A. Behavioral antecedents of peer social status. Child Devel. 54: 1386-1399, 1983.

Elder, G. Life course and human development. In: LERNER, R.M. (Ed.) Handbook of Child Psychology, Vol. 1: Theoretical Models of Human Development, New York: John Wiley \& Sons, 1998, pp. 939-991. 
Elliott, D.S., Ageton, S.S., Huizinga, D., Knowles, B.A., and Canter, R.J. The Prevalence and Incidence of Delinquent Behavior: 1976-1980. National Estimates by Sex, Race, Social Class and Other Selected Variables, Boulder, CO: Behavioral Research Institute, 1983.

Ennett, S.T. And Bauman, K.E. Peer group structure and adolescent cigarette smoking: A social network analysis. J. Hlth Social Behav. 34: 226-236, 1993.

Famularo, R., Stone, K., Barnum, R. and Wharton, R. Alcoholism and severe child maltreatment. Amer. J. Orthopsychiat. 56: 481-485, 1986.

Farrow, J.A., Deisher, R.W., Brown, R., Kulig, J.W. and Kipke, M.D. Health and health needs of homeless and runaway youth: A position paper of the Society for Adolescent Medicine. J. Adolesc. Hith 13: 717-726, 1992

Gomes-Schwartz, B., Horowitz, J. and Sauzier, M. Severity of emotional distress among sexually abused preschool, school-age, and adolescent children. Hosp. Commun. Psychiat. 36: 503-508, 1985.

Gottfredson, M.R. And Hirschi, T. A General Theory of Crime, Stanford, CA: Stanford Univ. Press, 1990.

Hagan, J., McCarthy, B., Parker, P. and Climenhage, J.A. Mean Streets: Youth Crime and Homelessness, New York: Cambridge Univ. Press, 1997.

Harrison, P.A., Fulkerson, J.A. and Beebe, T.J. Multiple substance use among adolescent physical and sexual abuse victims. Child Abuse Negl. 21: 529-539, 1997.

Hawke, J.M., Jainchill, N. And DeLeon, G. The prevalence of sexual abuse and its impact on the onset of drug use among adolescents in therapeutic community drug treatment. J. Child Adolesc. Subst. Abuse 9 (3): 35-49, 2000.

Hawkins, J.D, Catalano, R.F. and Miller, J.Y. Risk and protective factors for alcohol and other drug problems in adolescence and early adulthood. Psychol. Bull. 112: 64-105, 1992.

IrEland, T. AND WIDOM, C.S. Childhood victimization and risk for alcohol and drug arrests. Int. J. Addict. 29: 235-274, 1994.

Janus, M.D., Burgess, A.W. And McCormack, A. Histories of sexual abuse in adolescent male runaways. Adolescence 22: 405-417, 1987.

Jessor, R. And Jessor, S.L. Problem Behavior and Psychosocial Development: A Longitudinal Study of Youth, San Diego, CA: Academic Press, 1977.

Johnston, L.D., O’Malley, P.M. and Bachman, J.G. Monitoring the Future: National Survey Results on Drug Use, 1975-2000, Vol. 1, NIH Publication No. 01-4924, Bethesda, MD: Department of Health and Human Services, 2001.

Jöreskog, K.G. And Sörbom, D. LISREL 8: User's Reference Guide, Chicago, IL: Scientific Software, 1993.

Kandel, D.B. AND ANDREws, K. Processes of adolescent socialization by parents and peers. Int. J. Addict. 22: 319-342, 1987.

Kilpatrick, D.G., Acierno, R., Saunders, B., Resnick, H.S., Best, C.L. AND SCHNURR, P.P. Risk factors for adolescent substance abuse and dependence: Data from a national sample. J. Cons. Clin. Psychol. 68: 19-30, 2000.

Kipke, M.D., Clatts, M.C., Garcia, D., Palmer, R.F., Anderson, J. and SeEman, G.M. Substance use and injection drug use behaviors among street youth in four U.S. cities. Paper presented at the annual meeting of the American Public Health Association, San Diego, CA, 1995a.

Kipke, M.D., Montgomery, S. And MacKenzie, R.G. Substance use among youth seen at a community-based health clinic. J. Adolesc. Hlth 14: 289-294, 1993.

Kipke, M.D., Montgomery, S.B., Simon, T.R. and Iverson, E.F. "Substance abuse" disorders among runaway and homeless youth. Subst. Use Misuse 32 (7-8): 969-986, 1997.

Kipke, M.D., Montgomery, S.B., Simon, T.R., Palmer, R.F. and Iverson, E.F. Homeless youth: Drug use patterns and HIV risk profiles according to peer group affiliation. Paper presented at the Third Science Symposium on HIV Prevention: Current Status and Future Directions, Flagstaff, AZ, 1995b.
Kipke, M.D., O’Connor, S., Palmer, R. and MacKenzie, R.G. Street youth in Los Angeles: Profile of a group at high risk for human immunodeficiency virus infection. Arch. Pediat. Adolesc. Med. 149: 513-519, 1995c.

Koopman, C., Rosario, M. and Rotheram-Borus, M.J. Alcohol and drug use and sexual behaviors placing runaways at risk for HIV infection. Addict. Behav. 19: 95-103, 1994.

KufELDt, K. AND Nimmo, M. Youth on the street: Abuse and neglect in the eighties. Child Abuse Negl. 11: 531-543, 1987.

LindBerg, F.H. And Distad, L.J. Survival responses to incest: Adolescents in crisis. Child Abuse Negl. 9: 521-526, 1985.

McCormack, A., Janus, M.-D. And Burgess, A.W. Runaway youths and sexual victimization: Gender differences in an adolescent population. Child Abuse Negl. 10: 387-395, 1986.

Maclean, M.G., Paradise, M.J. and Cauce, A.M. Substance use and psychological adjustment in homeless adolescents: A test of three models. Amer. J. Commun. Psychol. 27: 405-427, 1999.

National Network of Runaway and Homeless Youths. To Whom Do They Belong? Runaway, Homeless, and Other Youth in High-Risk Situations in the 1990s, Washington, DC: National Network of Runaway and Youth Services, 1991.

Patterson, G.R. Coercive Family Processes, Eugene, OR: Castalia, 1982.

Patterson, G.R., Dishion, T.J. And Bank, L. Family interaction: A process model of deviancy training. Aggress. Behav. 10: 235-267, 1984.

Ringwalt, C.L., Greene, J.M. And Robertson, M.J. Familial backgrounds and risk behaviors of youth with thrownaway experiences. J. Adolesc. 21: 241-252, 1998.

Robertson, M.J. Homeless Youth in Hollywood: Patterns of Alcohol Use, Berkeley, CA: Alcohol Research Group, School of Public Health, University of California at Berkeley, 1989.

Robertson, M.J., Koegel, P. and Ferguson, L. Alcohol use and abuse among homeless adolescents in Hollywood. Contemp. Drug Probl. 16: 415-452, 1989.

Rotheram-Borus, M.J., Mahler, K.A., Koopman, C. and Langabeer, K Sexual abuse history and associated multiple risk behavior in adolescent runaways. Amer. J. Orthopsychiat. 66: 390-400, 1996.

Russell, M., Henderson, C. And Blume, S.B. Children of Alcoholics: A Review of the Literature, New York: Children of Alcoholics Foundation, 1985.

Sher, K.J., Walitzer, K.S., Wood, P.K. and Brent, E.E. Characteristics of children of alcoholics: Putative risk factors, substance use and abuse, and psychopathology. J. Abnorm. Psychol. 100: 427-448, 1991.

Silbert, M.H. AND PINEs, A.M. Sexual child abuse as an antecedent to prostitution. Child Abuse Negl. 5: 407-411, 1981.

Singer, M.I., Petchers, M.K. And Hussey, D. The relationship between sexual abuse and substance abuse among psychiatrically hospitalized adolescents. Child Abuse Negl. 13: 319-325, 1989.

SMART, R.G. AND AdLAF, E.M. Substance use and problems among Toronto street youth. Brit. J. Addict. 86: 999-1010, 1991.

Smart, R.G. And Ogborne, A.C. Street youth in substance abuse treatment: Characteristics and treatment compliance. Adolescence 29: 733$745,1994$.

Stice, E., Barrera, M. And Chassin, L. Relation of parental support and control to adolescents' externalizing symptomatology and substance use: A longitudinal examination of curvilinear effects. J. Abnorm. Child Psychol. 21: 609-629, 1993.

Straus, M.A. and Gelles, R.J. Physical Violence in American Families: Risk Factors and Adaptations to Violence in 8,145 Families, New Brunswick, NJ: Transaction, 1990.

Vicary, J.R. And Lerner, J.V. Parental attributes and adolescent drug use. J. Adolesc. 9: 115-122, 1986.

Welsh, L.A., Archambault, F.X., Janus, M.D. and Brown, S.W. Running for Their Lives: Physical and Sexual Abuse of Runaway Adolescents, New York: Garland, 1995. 
Whitbeck, L.B. And Hoyt, D.R. Nowhere to Grow: Homeless and Runaway Adolescents and Their Families, Hawthorne, NY: Aldine de Gruyter, 1999.

Whitbeck, L.B., Hoyt, D.R. And Ackley, K.A. Families of homeless and runaway adolescents: A comparison of parent/caretaker and adolescent perspectives on parenting, family violence, and adolescent conduct. Child Abuse Negl. 21: 517-528, 1997.

Whitbeck, L.B., Hoyt, D.R. And Yoder, K.A. A risk-amplification model of victimization and depressive symptoms among runaway and homeless adolescents. Amer. J. Commun. Psychol. 27: 273-296, 1999.

Whitbeck, L.B. and Simons, R.L. Life on the streets: The victimization of runaway and homeless adolescents. Youth Soc. 221: 108-125, 1990.
WhitBeck, L.B. And Simons, R.L. A comparison of adaptive strategies and patterns of victimization among homeless adolescents and adults. Viol. Vict. 8: 135-152, 1993.

Widom, C.S., Ireland, T. and Glynn, P.J. Alcohol abuse in abused and neglected children followed-up: Are they at increased risk? J. Stud. Alcohol 56: 207-217, 1995.

WINDLE, M. Substance use and abuse among adolescent runaways: A fouryear follow-up study. J. Youth Adolesc. 18: 331-344, 1989.

Yates, G.L., MacKenzie, R., Pennbridge, J. and Cohen, E. A risk profile comparison of runaway and non-runaway youth. Amer. J. Publ. Hlth 78: 820-821, 1988. 